02

\title{
Оптические свойства монокристаллического германия в терагерцовой области спектра
}

\author{
(С) И.А. Каплунов ${ }^{1}$, А.И. Колесников ${ }^{1}$, Г.И. Кропотов ${ }^{2}$, В.Е. Рогалин ${ }^{1,3}$ \\ ${ }^{1}$ Тверской государственный университет, \\ 170100 Тверь, Россия \\ 2 „Тидекс“, \\ 194292 Санкт-Петербург, Россия \\ ${ }^{3}$ Национальный центр лазерных систем и комплексов „Астрофизика“, \\ 125424 Москва, Россия \\ ฯ e-mail: kaplunov.ia@tversu.ru
}

Поступила в редакцию 05.07.2018 г.

В окончательной редакции 19.11.2018 г.

Принята к публикации 20.11.2018 г.

\begin{abstract}
Экспериментально исследовано пропускание собственного и легированного сурьмой и галлием монокристаллического германия в терагерцовой области спектра. Показано, что собственный германий в области $160-220 \mu$ m имеет потери на уровне $\sim 0.5 \mathrm{~cm}^{-1}$, что сравнимо с кремнием. Сечение поглощения свободных носителей заряда в кремнии и германии заметно различается, что может быть вызвано различием во взаимодействии носителей заряда с фононами.
\end{abstract}

DOI: $10.21883 /$ OS.2019.03.47365.194-18

\section{Введение}

Длинноволновую часть электромагнитного спектра $\left(\sim 3 \mathrm{~mm}-30 \mu \mathrm{m}, 3 \mathrm{~cm}^{-1}-300 \mathrm{~cm}^{-1}\right)$ принято называть терагерцовое (ТГц) излучение [1]. Терагерцовое излучение, в отличие от более коротких волн, может проникать в органические материалы, такие как кожа, пластики, одежда или бумага. Низкая энергия фотона не вызывает повреждений, связанных с ионизирующими излучениями (такими как рентгеновские лучи, например), поэтому активно исследуется возможность замены медицинских рентгеновских аппаратов на аппараты с терагерцовыми источниками. Терагерцовое излучение не проникает в металлы, что позволяет его использовать в текущем производственном контроле качества готовой продукции. Представляет большой интерес использование ТГц излучения в таких приложениях, как: контроль безопасности, проверка упаковок, характеризация полупроводников, анализ химического состава, биохимические исследования, дистанционное обнаружение взрывчатых, отравляющих и наркотических веществ и т.д.

Терагерцовый диапазон электромагнитного спектра исследуется уже около ста лет [1]. Для этой области непросто подобрать подходящие оптические материалы. Для источников малой интенсивности обычно используются сравнительно недорогие органические материалы [2]. Применение этих материалов в лазерах ограничено. До недавнего времени в лазерной технике ТГц диапазон почти не использовался, хотя впервые возможность создания такого лазера была продемонстрирована в 1970 г. [3]. Однако в настоящее время активно ведутся работы по накачке ТГц сред мощным излучением $\mathrm{CO}_{2}$-лазера [4]. Это вызывает активный интерес к поиску оптических материалов, прозрачных в этом диапазоне. Германий для этих применений интересен тем, что он прозрачен как в ТГц области, так и на длине волны $\mathrm{CO}_{2}$-лазера [5]. В инфракрасной технике [6,7] германий применяется для изготовления оптических деталей приборов и устройств различного назначения. Это изделия в виде защитных окон, линз, акустооптических элементов (оптические приборы наземного, морского, воздушного базирования, для космических аппаратов). Германий применяется для высокоэффективных фотоэлектрических преобразователей (солнечные батареи), а также используется в качестве детекторов в датчиках ионизирующих излучений.

Германий $(\mathrm{Ge})$ и кремний $(\mathrm{Si})$ являются наиболее исследованными материалами благодаря их широчайшему использованию в электронике и оптике ИК диапазона. Однако применение германия в значительной степени ограничено дефицитом этого материала в природе. Разработчики стараются использовать Ge, как правило, в тех случаях, когда он демонстрирует явное преимущество над кремнием. Это прежде всего оптика ИК диапазона (атмосферное окно 8-14 $\mu \mathrm{m}$ ), где кремний имеет заметное поглощение. В ТГц диапазоне кремний изначально занял настолько прочные позиции, что возможности германия до сих пор практически не рассматривались, хотя этот материал и исследовался ранее в ТГц диапазоне $[8,9]$. В ТГц диапазоне представляет интерес использование германия для изготовления активных элементов акустооптических устройств [10,11]. Высокие потери на отражение могут быть скомпенсированы путем создания на поверхности периодических рельефных структур с высокой степенью регулярности и периодом меньше длины волны излучения [12]. Кроме 
того, германий может быть использован для применения в мультиспектральных тепловизионных приборах ИК + ТГц диапазонов, а также в лазерах ТГц диапазона, накачиваемых $\mathrm{CO}_{2}$-лазером. Настоящая работа выполнена с целью углубленного исследования оптического пропускания чистого и легированного примесями разного типа проводимости германия в терагерцовом спектральном диапазоне.

\section{Методика эксперимента}

Эксперименты проводились с помощью фурьеспектрометров Bruker Vertex 70 и Bruker IFS 66v/s в спектральном диапазоне $1.3-670 \mu \mathrm{m}$, а в диапазоне 100-1500 $\mu \mathrm{m}$ на приборе Tera K8 Menlo Systems.

Германий выращивался из расплава методом Чохральского в кристаллографическом направлении $\langle 111\rangle$. Исследовали монокристаллы, выращенные из нелегированного расплава, а также монокристаллы, легированные сурьмой и галлием. На легированных кристаллах изучалось влияние проводимости на пропускание. Как показано в [11], обработка поверхности оказывает влияние на пропускание в ТГц спектральном диапазоне, поэтому образцы для исследований диаметром $39 \mathrm{~mm}$ и толщиной $10 \mathrm{~mm}$ полировались с допусками $N<1$, $\Delta N<0.5$. Фактические значения коэффициента пропускания определяли с фотометрической точностью $0.1 \%$.

Расчет коэффициента ослабления $\alpha$ проводился с учетом многократных отражений по известной $[13,14]$ формуле

$$
T=\frac{(1-R)^{2} e^{\alpha h}}{e^{2 \alpha h}-R^{2}}
$$

где: $T$ и $R$ - коэффициенты пропускания и отражения, $h$ - толщина образца.

Зависимость показателя преломления германия $n$ от длины волны $\lambda$ в рассматриваемом спектральном диапазоне получена с использованием полинома наилучшего приближения $(\lambda$ в $\mu \mathrm{m})$ :

$$
\begin{aligned}
n(\lambda)= & 4+0.001106337-0.00314503 / \lambda \\
& +0.492812 / \lambda^{2}-0.601906 / \lambda^{3}+0.982897 / \lambda^{4} .
\end{aligned}
$$

\section{Результаты эксперимента}

Спектральные зависимости легированных сурьмой и галлием монокристаллов с разным удельным электросопротивлением приведены на рис. 1 и 2.

На рис. 3 приведены спектры коэффициентов ослабления наиболее характерных образцов германия в диапазоне длин волн 60-1500 $\mu \mathrm{m}$. Наглядно видно, что с ростом длины волны потери снижаются, достигая в собственном германии величины $\sim 0.5 \mathrm{~cm}^{-1}$ (в диапазоне $160-220 \mu \mathrm{m})$ и далее монотонно возрастают. Причем потери растут с уменьшением удельного электросопротивления кристалла.

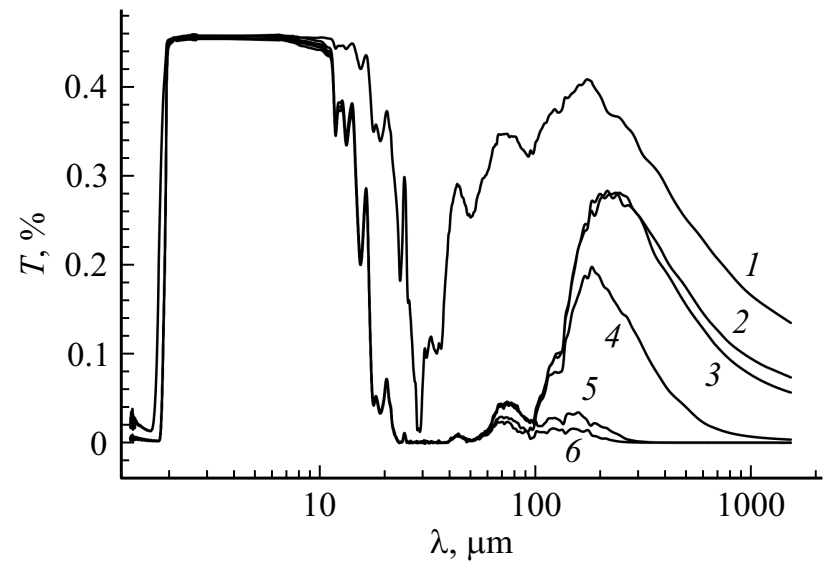

Рис. 1. Оптическое пропускание монокристаллического Ge: 1 - нелегированный $\mathrm{Ge}$ (толщина $1 \mathrm{~mm}$ ); 2 - нелегированный $\mathrm{Ge}$ (толщина $10 \mathrm{~mm}$ ); легированный сурьмой $\mathrm{Ge}$, удельное электросопротивление: 46 (3), 20 (4), 5 (5), $2.7 \mathrm{Ohm} \cdot \mathrm{cm}$ (6) (спектры 3-6 получены на образцах толщиной $10 \mathrm{~mm}$ ).

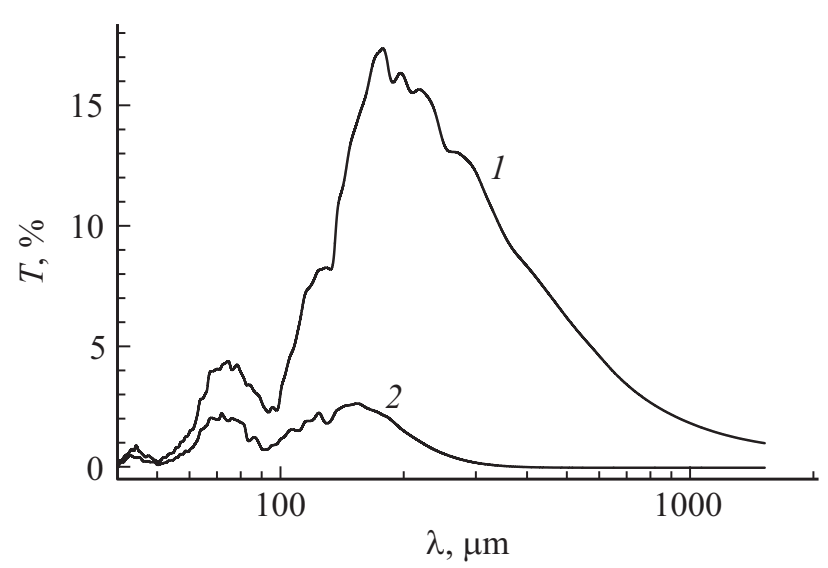

Рис. 2. Оптическое пропускание монокристаллического германия, легированного галлием. Удельное электросопротивление: 16 (1), 4.2 (2) $\mathrm{Ohm} \cdot \mathrm{cm}$ (толщина образцов $10 \mathrm{~mm}$ ).

В ИК спектральном диапазоне кристаллы германия электронного типа проводимости имеют более высокое пропускание, что определяется малым сечением поглощения электронов по сравнению с дырками [6,15-17]. В области $10 \mu \mathrm{m}$ минимальное поглощение имеют не собственные кристаллы, а материал $n$-типа с удельным электросопротивлением 5-10 Ohm $\cdot \mathrm{cm}[6,15]$.

Результаты настоящего эксперимента показывают существенный рост поглощения легированных кристаллов в ТГц диапазоне. В ТГц спектральном диапазоне максимальным пропусканием обладает нелегированный германий (рис. 3) с удельным электросопротивлением $47 \mathrm{Ohm} \cdot \mathrm{cm}$. Увеличение концентрации примеси как электронной, так и дырочной, приводит к возрастанию поглощения.

Сравнение оптического пропускания полупроводников кремния и германия [18] в диапазоне длин волн более $25 \mu \mathrm{m}$ показывает высокие значения пропуска- 


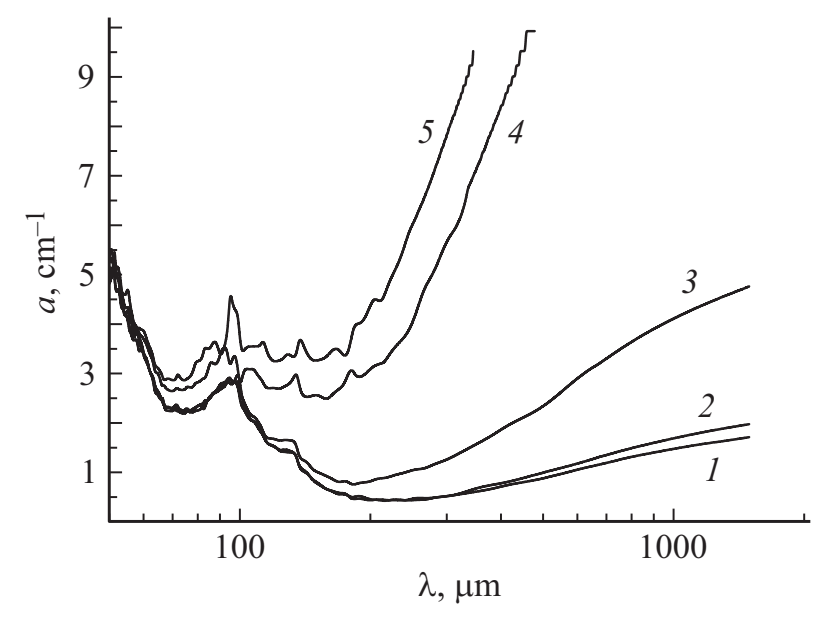

Рис. 3. Коэффициент ослабления $\mathrm{Ge}-$ нелегированный (1); легирование сурьмой: 46 (2), 20 (3), 5 (4), $2.7 \mathrm{Ohm} \cdot \mathrm{cm}$ (5).

ния кремния (около 55\%) по сравнению с германием. Прежде всего, это обусловлено различной величиной френелевского отражения (в ИК области показатель преломления $\mathrm{Ge} \sim 4.0$, а для $\mathrm{Si} \sim 3.42$ ). Причем максимальные значения наблюдалась для кремния, полученного бестигельной зонной плавкой с удельным электросопротивлением несколько $\mathrm{kOhm} \cdot \mathrm{cm}$. Следует предположить, что основное поглощение в рассматриваемом спектральном диапазоне имеет место на свободных носителях заряда (как собственных, так и примесных), а в чистом кремнии и германии их концентрации существенно различаются (собственный Ge: $47 \mathrm{Ohm} \cdot \mathrm{cm}, E=0.67 \mathrm{eV}, n=2.5 \cdot 10^{13} \mathrm{~cm}^{-3}$; собственный $\left.\mathrm{Si}: 2 \mathrm{kOhm} \cdot \mathrm{cm}, E=1.12 \mathrm{eV}, n=5 \cdot 10^{10} \mathrm{~cm}^{-3}\right)$.

Исходя из этих рассуждений, поглощение в ТГц области в германии должно быть заметно выше, чем в кремнии. Однако если сопоставить наши результаты по германию (рис. 3 , в области $\lambda \sim 160-220 \mu \mathrm{m}$ ) и данные по кремнию, приведенные в [19], то они свидетельствуют, что коэффициент ослабления примерно совпадает и равен $\sim 0.5 \mathrm{~cm}^{-1}$. В то же время (рис. 1,2) по спектрам пропускания видно, что в области 160-220 $\mu \mathrm{m}$ зона многофононного поглощения заканчивается, и в более длинноволновой области, казалось бы, можно ожидать меньшее поглощение. Однако в этой области наблюдается рост потерь, вызванный другим механизмом - поглощением на свободных носителях заряда, как известно, растущим с увеличением длины волны.

В германии в ближнем и среднем ИК диапазонах наблюдается существенное различие поглощения в монокристаллах с разным типом проводимости. На длине волны $10.6 \mu \mathrm{m}$ соотношение между сечениями поглощения электронов и дырок по разным источникам составляет $\sim 16-100$. Поэтому в области $10 \mu \mathrm{m}$ минимальное поглощение имеют не собственные кристаллы, а легированные донорной примесью. Однако в ТГц области сечения поглощения электронов и дырок почти сравнялись. Это наглядно видно на рис. 1. Если в области 25-50 $\mu \mathrm{m}$ влияние удельного электросопротивления на пропускание наших образцов, легированных сурьмой, практически не заметно, то в области 120-220 $\mu \mathrm{m}$ оно наблюдается воочию. Тем не менее в легированных галлием образцах германия в ТГц области поглощение несколько выше, чем в легированных сурьмой. При близких концентрациях примеси $(2.5-3.0) \cdot 10^{14} \mathrm{~cm}^{-1}$ (концентрация соответствует кристаллам с удельным сопротивлением $5 \mathrm{Ohm} \cdot \mathrm{cm}$ (сурьма) и $16 \mathrm{Ohm} \cdot \mathrm{cm}$ (галлий)) пропускание легированных галлием кристаллов ниже на $\sim 2.5 \%$, а коэффициент ослабления выше в 1.45 раза (для длины волны $120 \mu \mathrm{m}$ ).

\section{Заключение}

Полученные нами результаты свидетельствуют, что сечение поглощения свободных носителей заряда в кремнии и германии заметно различается, что может быть вызвано различием во взаимодействии носителей заряда с фононами.

В отличие от ИК диапазона, в котором минимальное поглощение $\sim 0.02 \mathrm{~cm}^{-1}(\lambda=10.6 \mu \mathrm{m})$ наблюдается в кристаллах $n$-типа проводимости $5-10 \mathrm{Ohm} \cdot \mathrm{cm}$, в ТГц области минимальные потери $\sim 0.5 \mathrm{~cm}^{-1}$ наблюдаются в собственных кристаллах.

В области 160-220 $\mu \mathrm{m}$ коэффициент ослабления германия $\sim 0.5 \mathrm{~cm}^{-1}$, что сопоставимо с кремнием. Френелевские потери на отражение могут быть в значительной степени скомпенсированы путем создания на поверхности периодических рельефных структур с высокой степенью регулярности и периодом меньше длины волны излучения. Следовательно, оптические изделия из собственного монокристаллического германия могут быть использованы в ТГц диапазоне в области 120-300 $\mu \mathrm{m}$.

Работа выполнена с использованием ресурсов Центра коллективного пользования Тверского государственного университета при поддержке Минобрнауки России в рамках реализации государственного задания по научной деятельности (3.5786.2017/8.9).

\section{Список литературы}

[1] Glagoleva-Arkadieva A. // Nature. 1924. N 5. P. 640.

[2] Рогалин В.Е., Каплунов И.А., Кропотов Г.И. // Опт. и спектр. 2018. Т. 125. № 6. C. 851-863.

[3] Chang T.Y., Bridges T.J., Burkhardt E.G. // Appl. Phys. Lett. 1970. V. 17. P. 249-251.

[4] Tochitsky S.Ya., Ralph J.E., Sung C., Joshi C. // J. Appl. Phys. 2005. V. 98. P. 26101.

[5] Левинзон Д.И., Ровинский Р.Е., Рогалин В.Е., Рыкун Е.П., Трайнин А.Л., Ценина И.С., Шейхет Э.Г. // Изв. АН СССР. Сер. физ. 1979. Т. 43. № 9. С. 2001-2005.

[6] Ровинский Р.Е., Рогалин В.Е., Шершель В.А. // Изв. АН СССР. Сер. физ.. 1983. Т. 47. № 2. С. 406-409. Rovinskii R.E., Rogalin V.E., Shershel V.A. // Bull. Acad. Sci. U.S.S.R. Phys. ser. 1983. V. 47. P. 188-191. 
[7] Claeys L., Simoen E. Germanium.based technologies: from materials to devices. Berlin: Elsevier, 2007. 449 p.

[8] Loewenstein E.V., Smith D.R., Morgan R.L. // Appl. Opt. 1973. V. 12. N 2. P. $398-406$.

[9] Grischkowsky D., Keiding S., van Exter M., Fattinger Ch. // J. Opt. Soc. Am. B. 1990. V. 7. N 10. P. 2006-2015.

[10] Волошинов В.Б., Никитин П.А., Герасимов В.В., Князев Б.А., Чопорова Ю.Ю. // Квант. электрон. 2013. T. 43. № 12. C. 1139-1142. Voloshinov V.B., Nikitin P.A., Gerasimov V.V., Knyazev B.A., Choporova Yu.Yu. // Quant. Electron. 2013. V. 43. N 12. P. 1139-1142.

[11] Kaplunov I.A., Nikitin P.A., Voloshinov V.B., Kolesnikov A.I., Knyazev B.A. // J. Phys. Conf. Ser. 2016. V. 37. P. 012021.

[12] Soifer V.A. Computer design of diffractive optics. Cambridge Int. Sci. Publ. Ltd. \& Woodhead Publ. Ltd., 2012. 896 p.

[13] Курик М.В. // ЖПС. 1966. Т. 4. № 3. С. 275. Kurik M.V. // J. Appl. Spectr. 1966. V. 4. N 3. P. 199-201.

[14] Каплунов И.А., Колесников А.И., Талызин И.В., Седова Л.В., Шайович С.Л. // Оптический журнал. 2005. Т. 72. № 7. C. 76-84. Kaplunov I.A., Kolesnikov A.I., Talyzin I.V., Sedova L.V., Shaǐovich S.L. // J. Opt. Technol. 2005. V. 72. N 7. P. $564-571$.

[15] Каплунов И.А., Смирнов Ю.М., Колесников А.И. // Оптический журнал. 2005. Т. 72. № 2. С. 61-68. Kaplunov I.A., Smirnov Yu.M., Kolesnikov A.I. // J. Opt. Technol. 2005. V. 72. N 2. P. $214-220$.

[16] Hass H., Bendow B. // Appl. Optics. 1977. V. 16. N 11. P. 2882-2890.

[17] Hutchinson C.J., Lewis C., Savage J.A., Pitt A. // Appl. Optics. 1982. V. 21. N 8. P. 1490-1495.

[18] Handbook of Infrared Optical Materials. N.Y.: CRC Press, 1991. $630 \mathrm{p}$.

[19] THz Materials [электронный pecypc]. Режим доступа: http://www.tydexoptics.com/ru/products/thz_optics/ thz_materials/ 